\title{
Historiar la expropiación y el capitalismo. A propósito del libro Capitalismo y despojo. Perspectiva histórica sobre la apropiación universal de bienes y saberes
}

\author{
Vega, Renán. Capitalismo y despojo. Perspectiva histórica sobre la expropia- \\ ción universal de bienes y saberes. Bogotá, Impresol-Corporación Aury Sará \\ Marrugo-Prensa Alternativa Periferia, 2013.
}

Renán Vega Cantor es economista, historiador y doctor en estudios políticos de la Universidad París VIII; se desempeña como profesor titular de la Universidad Pedagógica Nacional en Bogotá. En esta obra se ocupa de estudiar el despojo como una de las características intrínsecas del capitalismo, desde una perspectiva histórica que se remonta hasta la primera modernidad en el siglo XV y que se ha expresado mediante cinco procesos: despojo de la tierra y la naturaleza, del cuerpo de los seres humanos al ser confinados a territorios o esclavizados, del producto de su trabajo, de su tiempo y de sus saberes. Se trata de formas de expropiación que pueden presentarse en forma simultánea, como en el mundo de hoy, aunque en ciertas épocas predomine una u otra.

La obra, estructurada en siete capítulos, estudia tanto los procesos de despojo como la resistencia de los sujetos. El punto de partida es una concepción marxista de la historia, como un intercambio entre los seres humanos y la naturaleza con miras a la satisfacción de las necesidades, fundado en una unidad entre el trabajador, las condiciones de producción y los saberes empleados, que se fragmentó con la emergencia del capitalismo en los albores del siglo XVIII. Una desintegración que corrió por cuenta del proceso de "acumulación originaria", sustentado en la expropiación de las condiciones de producción, el acceso a la tierra y la propiedad de los medios de producción; los saberes, acumulados por campesinos y artesanos durante generaciones; y los productos de trabajo, mediante formas de división, mecanización y automatización del trabajo.

El capítulo primero estudia la expropiación de la tierra y de la naturaleza, remontándose a los orígenes del colonialismo europeo en el siglo XV y la desposesión de americanos y africanos, que no se limitó a su fuerza de trabajo o a los bienes naturales de los territorios colonizados, sino que se proyectó sobre sus culturas, tradiciones, prácticas y saberes, particularmente en cuanto a agricultura, llevada a cabo mediante la violencia y legitimada en discursos de superioridad racial de los colonizadores. También resalta mecanismos característicos 
de la "acumulación originaria", como los cercamientos de tierras y bosques de uso común, transformados en derechos de propiedad privados en la Inglaterra del siglo XVIII, que están a la base de la imposición del régimen salarial y de la división social y sexual del trabajo, y que fueron resistidos con el rechazo a la proletarización mediante insurrecciones, revueltas milenaristas, motines de subsistencia e incluso la piratería.

Seguidamente, el autor examina las particularidades del despojo sobre los indígenas y pobladores africanos. Se trató de un "despojo absoluto", en la medida en que no solo se proyectó sobre su tiempo y sus riquezas materiales (metales preciosos con un valor de cambio para los colonizadores) y naturales (bienes naturales, biodiversidad, tierra, agua, bosques), sino también sobre su espíritu, su cultura, sus saberes y sus costumbres. Ahora bien, Vega demuestra que indígenas y africanos se sublevaron desde el momento mismo en que inició el despojo. Allí se destacaron líderes indígenas como Anacaona, Guarionex, Cotubano, Enriquillo, Guaicaipuro y Jacinto Canek. Pese al terror y al sadismo de la esclavización, vinculado directamente con los intereses de los grandes imperios y sus procesos de industrialización, los africanos resistieron con el cimarronaje y la fundación de palenques o quilombos, e incluso con rebeliones que empezaban en los mismos barcos negreros.

El capítulo tercero está enfocado en el análisis de la expropiación del producto del trabajo, es decir, en la separación de los productores de las condiciones de producción: a los artesanos se los priva de sus herramientas y sus saberes acumulados y a los campesinos de sus tierras, sus saberes, costumbres y cultura. Tecnologías como el taylorismo, implementado desde principios del siglo XX, centralizan procedimientos y expropian los saberes productivos de los trabajadores para optimizar los procesos de producción y beneficiar los capitalistas. De acuerdo con Vega, actualmente existe una apropiación del producto del trabajo intensificada gracias a los adelantos en las tecnologías informáticas y de las telecomunicaciones, implementadas por el posfordismo y el toyotismo.

Posteriormente, se examinan los mecanismos de expropiación del tiempo de los trabajadores, en un proceso que se retrotrae al uso de campanas en los monasterios de la baja Edad Media, pero que tiene su cénit en el uso de tecnologías para medir y mecanizar el tiempo de trabajo, empezando por el reloj. Tales tecnologías imponen el tiempo intenso y mecánico del capitalismo sobre los ritmos naturales de la vida y de la producción. Frente a esta imposición se destacan formas de resistencia, desde la adquisición de los relojes por parte de los trabajadores para contrarrestar el monopolio que los patrones tenían sobre el manejo del tiempo, hasta la reivindicación del "derecho a la pereza", en un primer momento, y el acortamiento de la jornada laboral, más tarde. Hoy en día, tecnologías como los teléfonos celulares o el internet han posibilitado la subsunción del tiempo de la vida en el tiempo del trabajo, hasta tal punto que aún las personas que trabajan en sus hogares tienen creciente dificultad para "desconectarse" y separar su vida familiar y cotidiana de su tiempo de trabajo.

El capítulo quinto analiza las implicaciones de la división social, técnica y sexual del trabajo sobre la expropiación de saberes. Vega sostiene que la división del trabajo cobra sentido no solo para optimizar los procesos productivos, sino también para expropiar los saberes, mediante la ruptura de la unidad que el 
productor mantenía con sus medios de producción y la totalidad o buena parte de los procesos productivos. Ahora los conocimientos se fragmentan en distintos operarios con diversas funciones, de tal forma que el productor desconoce el proceso de producción. Ello es posible con tecnologías como el taylorismo y el fordismo. En el mundo contemporáneo, el posfordismo y el toyotismo suponen que los trabajadores se apropian de diversos saberes y son capaces de trabajar autónomamente; sin embargo, sus lógicas son contradictorias, puesto que muchas veces la recuperación de saberes es funcional a la expropiación: por ejemplo, el "trabajo autónomo", que expresa la creciente dificultad para "desconectarse" del trabajo, termina por ahondar la expropiación del tiempo, ahora mediante mecanismos de flexibilización y precarización laboral, sujetos a un mayor control gracias a las tecnologías informáticas.

Luego el profesor Vega se concentra en el estudio del papel de las máquinas en la expropiación de los saberes. En su criterio, las máquinas sustituyen inicialmente la destreza de los productores, lo cual tiene como efecto la optimización de la explotación. Pero, además, las máquinas rompen el control de los procesos productivos y las habilidades de organizaciones de artesanos como los gremios, apoderándose de un saber acumulado e impidiendo la reapropiación de ese saber por parte de los productores. Sucede que las destrezas se adaptan a los mecanismos de la máquina, de tal forma que el trabajo de los obreros es privado de la inventiva y se vuelve mecánico. El saber es objetivado en las máquinas al tiempo que se priva a los trabajadores de la posibilidad de acceder a ese saber y de la necesidad de recurrir a su inteligencia e inventiva. Según el autor, en la actualidad "asistimos al despojo general de los saberes en todo el mundo" (p. 285). Las TIC han profundizado esa dinámica de despojo y, mediante la creciente indistinción que promueven entre tiempo de trabajo y tiempo libre o vida, han profundizado la expropiación. Por ejemplo, los computadores, que presuntamente potencian nuestras capacidades, implican que cada vez tenemos más dependencia de ellos para realizar tareas tan cotidianas como operaciones aritméticas, así como menores posibilidades de desarrollar ciertas capacidades y tener autonomía para formular y resolver problemas, memorizar, etc., con lo que la máquina ha terminado por apoderarse de muchos de nuestros saberes y destrezas, poniéndolos al servicio del capitalismo por la vía del consumo o de la producción.

Finalmente, el capítulo séptimo recupera el legado de los "luditas", concebido como la búsqueda de otro tipo de relación con la tecnología. Estos sujetos cuyas acciones de resistencia afectaron el naciente capitalismo en el siglo XVIII, querían defender su forma de vida, su relativa independencia, sus costumbres, sus valores y su honor y, como es sabido, para ello acudían a la destrucción de ciertas máquinas vinculadas al despojo. Hoy los mecanismos del despojo también afectan algunas formas de vida que hacen pertinente la recuperación de los cuestionamientos que entonces se plantearon, tales como ¿existe otra forma de relacionarse con la tecnología?, ¿tiene algún límite ético o moral el desarrollo tecnológico?, entre otros.

En fin, el libro del profesor Vega tiene una interesante apuesta por la didáctica; no renuncia al rigor académico e historiográfico, pero al mismo tiempo articula un lenguaje y un estilo dirigidos a un público amplio. Cada uno de los argumentos despliega explicaciones teóricas de los mecanismos por medio de 
los cuales se produce cada forma de despojo, aunados a una reconstrucción histórica con abundantes descripciones de casos, a manera de ejemplos, e incluso muchas veces se echa mano de la literatura, todo lo cual permite comprender cabalmente el funcionamiento de las formas de despojo, tanto en una perspectiva de largo plazo como en la actualidad. Es destacable también el recurso a una completa historiografía sobre el problema en cuestión que se manifiesta en un amplio aparato crítico.

En términos teóricos y metodológicos cabe destacar lo que Vega denomina el "ludismo epistemológico" (p. 18), un enfoque que se esfuerza por develar las consecuencias sociales y políticas de los artefactos tecnológicos, privilegiando el análisis de sus impactos sobre las personas en lugar de enfatizar únicamente en los artefactos en sí mismos. Tal vez una de las tesis más polémicas de la obra es aquella que sostiene que la tecnología no puede tener un funcionamiento neutral sino, por el contrario, obedece al entramado de relaciones sociales en donde tiene lugar su desarrollo e implementación y, por consiguiente, responde a unos intereses determinados y tiene consecuencias contradictorias. Por ejemplo, los ordenadores personales y los teléfonos celulares solo son concebibles en sociedades individualistas y es en el marco de las relaciones sociales del capitalismo donde hay que ponderar sus consecuencias.

La obra se inspira en los análisis de Marx para comprender el devenir histórico y articular pasado y presente. Sin embargo, se trata de una lectura abierta del filósofo alemán, que impide al autor seguir un canon determinado. En este sentido es destacable la manera como su enfoque articula la explicación de los mecanismos de despojo de bienes materiales, con aquellos dirigidos al despojo de la cultura en su sentido más amplio (saberes, tradiciones, relaciones sociales, imaginarios, símbolos, creencias, etc.).

Con todo, cabe señalar por lo menos una cuestión problemática subyacente. Por momentos hay una visión que absolutiza las consecuencias negativas de los procesos de despojo y del desarrollo del capitalismo. Obviamente, esto es consecuente con el punto de vista crítico del libro. Sin embargo, tiene serias implicaciones cuando se trata de examinar el papel de la tecnología y las posibilidades de resistencia y emancipación, entre otras cosas.

Aunque el autor llama la atención sobre las consecuencias contradictorias de la tecnología, pasa por alto el hecho de que, aún cuando esta se desarrolla en un entramado de relaciones capitalistas y es por tanto funcional a estas, es necesario un cierto nivel de desarrollo tecnológico, o en otros términos un nivel de desarrollo de las "fuerzas productivas", para posibilitar una sociedad justa como la que imaginaban Marx y los marxistas, que haga realidad los principios "de a cada cual según sus capacidades, a cada cual según sus necesidades", y "el libre desarrollo de cada uno como condición del libre desarrollo de todos". Una evaluación de las consecuencias del desarrollo tecnológico en el mundo contemporáneo no debería pasar por alto este asunto.

Por otra parte, esa mirada un tanto unidireccional sobre los mecanismos de despojo y el desarrollo del capitalismo tiende a absolutizar los procesos de alienación y dominación, hasta un punto donde se hace francamente difícil pensar posibilidades de resistencia y emancipación. Por ejemplo, respecto a la expropiación implementada por la esclavitud, Vega sostiene que "era de tal alcance 
que los esclavos fueron reducidos a ser simples máquinas parlantes de producción (como los llamaría Aristóteles)" (p. 91). Si así hubiese ocurrido efectivamente, si los esclavizados se hubieran convertido en "máquinas parlantes", no se explicarían las formas de resistencia a las que el autor hace referencia. Ello implica que nunca el dominio sobre la vida es absoluto, que siempre hay resquicios, por pequeños que sean, desde donde es posible forjar proyectos emancipatorios. Tal idea habría enriquecido sus análisis sobre las formas de despojo basadas en las tecnologías de la información y la comunicación del mundo contemporáneo.

Edwin Cruz Rodríguez ${ }^{1}$

Profesor e investigador de la Universidad Nacional de Colombia, Bogotá-Colombia ecruzr@unal.edu.co

1 Politólogo. Magíster en análisis de problemas políticos, económicos e internacionales contemporáneos. 